Article

\title{
Rapid Removal of Zinc(II) from Aqueous Solutions Using a Mesoporous Activated Carbon Prepared from Agricultural Waste
}

\author{
Xiaotao Zhang ${ }^{1,2,+}$ (D), Yinan Hao ${ }^{2,+}$, Ximing Wang ${ }^{2, *}$ (1) and Zhangjing Chen ${ }^{3}$ \\ 1 College of Science, Inner Mongolia Agricultural University, Hohhot 010018, China; lianzixiaotao@163.com \\ 2 College of Material Science and Art Design, Inner Mongolia Agricultural University, Hohhot 010018, China; \\ nanyihao83@163.com \\ 3 Department of Sustainable Biomaterials Virginia Tech University, Blacksburg, VA 24061, USA; \\ chengo@vt.edu \\ * Correspondence: wangximing@imau.edu.cn \\ + Contributed equally to this paper.
}

Received: 5 August 2017; Accepted: 25 August 2017; Published: 28 August 2017

\begin{abstract}
A low-cost activated carbon (XSBLAC) prepared from Xanthoceras Sorbifolia Bunge hull via chemical activation was investigated to determine its adsorption and desorption properties for zinc(II) ions from aqueous solutions. XSBLAC was characterized based on its $\mathrm{N}_{2}$-adsorption/desorption isotherm, EDX, XRD, SEM and FTIR results. An adsorption study was conducted in a series of experiments to optimize the process variables for zinc(II) removal using XSBLAC. Modeling the adsorption kinetics indicated good agreement between the experimental data and the pseudo-second-order kinetic model. The Langmuir equilibrium isotherm fit the experimental data reasonably well. The calculated enthalpy $\left(\Delta H^{0}\right)$, entropy $\left(\Delta S^{0}\right)$ and Gibbs free energy $\left(\Delta G^{0}\right)$ values revealed the endothermic and spontaneous nature of the adsorption process. $\mathrm{HNO}_{3}$ displayed the best desorption performance. The adsorption mechanism was investigated in detail through FTIR and SEM/EDX spectroscopic analyses. The results suggested that XSBLAC is a potential biosorbent for removing zinc(II) from aqueous solutions.
\end{abstract}

Keywords: activated carbon; adsorption; zinc(II); desorption; mechanism

\section{Introduction}

Zinc(II) is frequently found in effluents discharged from industries, such as electroplating, pigments, battery manufacturing units, mining, metallurgy and municipal wastewater treatment plants. Zinc(II) is a well-known toxic metal ion and can threaten human life by bioaccumulating in the food chain. The World Health Organization recommended a maximum acceptable zinc concentration in drinking water of $5.0 \mathrm{mg} / \mathrm{L}$ [1]. The removal of zinc(II) ions or decreasing its concentration to the permitted levels before discharge is necessary to prevent deleterious effects on the ecosystem and public health [2].

Numerous methods have been employed to remove zinc(II) ions from wastewater, including precipitation, coagulation, ion exchange, membrane filtration, and electrolysis [3-7]. The cost and the generation of harmful wastes are important parameters relevant to most of these processes, especially for low concentrations of zinc(II). Currently, adsorption is regarded as a powerful technology for removing zinc(II) from aqueous solutions. Commercial activated carbon (AC) has been studied as an adsorbent for wastewater treatment; it has highly developed porosity, a large internal surface area, and relatively high mechanical strength [8]. However, manufacturing AC is very expensive [9]. To overcome this disadvantage, AC can be produced from a wide variety of raw and low-cost 
agricultural waste byproducts, including coconut shell, pecan shell, rice husk, oil palm shell, sugarcane bagasse, palm shell, and sawdust [10-17].

The production of AC from agricultural by-products is an increasingly interesting research field because it addresses the problem of the disposal of agro-residues. As the major source of energy tree species, Xanthoceras Sorbifolia Bunge has been widely and extensively cultivated in northern areas, especially the Inner Mongolia autonomous region of China, which has played a very significant role in the agricultural industry. Moreover, the Inner Mongolia region owns lots of processing industrial enterprises, which often produce a number of pollutants containing heavy metals. Therefore, we could efficiently utilize the biomass resources of Xanthoceras sorbifolia Bunge, preparing it as a potential high adsorbent and applying it to industrial wastewater for the purpose of "waste to manage waste". It is an attractive method to solve issues related to the sustainable development of industrialization in the north of China. From this point of view, the way in which agriculture is combined with industry of the local region to manage the ecological environment is the novelty of this work. In practice, Xanthoceras Sorbifolia Bunge hull (XSBL) is a by-product of production. XSBL is available in large quantities at no cost and could be a good basis for the development of adsorbent materials. Currently, the existing literature contains no information regarding the removal of zinc(II) using Xanthoceras Sorbifolia Bunge hull AC (XSBLAC).

The present work aims to prepare AC from XSBL via chemical activation using $\mathrm{H}_{3} \mathrm{PO}_{4}$ and characterize its ability to treat zinc(II)-containing wastewater. This XSBLAC production process is novel because it adopts the National Invention Patent method [18]. The properties of XSBLAC are investigated by analyzing $\mathrm{N}_{2}$ adsorption/desorption, energy dispersive spectrometry (EDX), $\mathrm{X}$-ray diffraction (XRD), scanning electron microscopy (SEM) and Fourier transform infrared spectroscopy (FTIR) results. Furthermore, the adsorption and desorption capacities of zinc(II) are observed in detail. Each factor influencing the adsorption and desorption behavior of XSBLAC, including the initial concentration of zinc(II), $\mathrm{pH}$ value, adsorption temperature, adsorption time, $\mathrm{HNO}_{3}$ concentration, desorption temperature and desorption time, is systematically studied using various scenarios. The adsorption kinetics and isotherms on XSBLAC are determined; the enthalpy $\left(\Delta H^{0}\right)$, entropy $\left(\Delta S^{0}\right)$ and Gibbs free energy $\left(\Delta G^{0}\right)$ values are calculated; and the mechanism of zinc(II) adsorption is discussed based on Fourier transform infrared (FTIR) and SEM/energy-dispersive X-ray (EDX) spectroscopic analyses. Finally, exploratory research results regarding the recycling application of XSBLAC offer a reference for zinc(II) removal, and its regeneration ability is evaluated after five adsorption/desorption cycles, showing good recycling ability.

\section{Experiments}

\subsection{Materials}

The XSBL used in this study as a raw material was collected from Chifeng, China. Prior to use, the sample was washed with hot deionized water to remove dirt particles, dried in the sun for a specific period of time, ground in a high-speed rotary cutting mill, and screened to a particle size of $0.5-0.8 \mathrm{~mm}$ for experimental use. A stock solution of zinc(II) $(1000 \mathrm{mg} / \mathrm{L})$ was prepared using analytical reagent (A.R.)-grade nitrate salts purchased from Tianjin Beilian Fine Chemicals Co., Ltd. (Tianjin, China). All other chemicals were reagent grade and were used without further purification. All solutions were prepared using deionized water.

\subsection{AC Preparation}

Solid XSBL residue was washed to neutrality using deionized water and dried at $100{ }^{\circ} \mathrm{C}$ for $24 \mathrm{~h}$ in a hot air oven (Memmert VO400, Schwabach, Germany). Subsequently, the dried mass was soaked in $\mathrm{H}_{3} \mathrm{PO}_{4}(85 \mathrm{wt} \%)$ and magnetically stirred (500 rpm) for $1 \mathrm{~h}$. The impregnation ratio was calculated as the ratio of the weight of $\mathrm{H}_{3} \mathrm{PO}_{4}$ in solution to the weight of the XSBLBL used. The material was carbonized at $500{ }^{\circ} \mathrm{C}$ in a tube furnace (FSX2-12-15N, Tianjin, China) for $4 \mathrm{~h}$. The sample was then 
cooled to room temperature in a nitrogen atmosphere and washed with deionized water until the $\mathrm{pH}$ level stabilized. It was dried in an oven overnight at $120^{\circ} \mathrm{C}$, ground, and finally sieved to 200 mesh [18] using standard sieves (Model $\Phi 200$ ). Then, this carbon powder was stored in an airtight packet for experimental use.

\subsection{Adsorption Studies}

An amount of XSBLAC $0.1000 \mathrm{~g}$ (BS210S, Sartorius, Gottingen, Germany) was accurately weighed and added to $50 \mathrm{~mL}$ of zinc(II) solution with a known concentration. The suspension was stirred at a uniform speed of $120 \mathrm{rpm}$ in a thermostatic shaker (SHA-C, Zhangjiagang, China), and its $\mathrm{pH}$ was adjusted using a certain amount of NaAc-HAc solution with a pH meter (PB-10, Sartorius, Germany). When the adsorption equilibrium was reached, the mixture was centrifuged at $6000 \mathrm{rpm}$ for $10 \mathrm{~min}$ (H2050R, Changsha, China). The residual concentration of zinc(II) in the supernatant was determined using an ultraviolet (UV)-Visible spectrophotometer (TU-1901, Beijing, China). The adsorption experiments were conducted with different initial zinc(II) concentrations, $\mathrm{pH}$ values, adsorption temperatures and times. Considering the experimental errors, three experiments were run in parallel under the same conditions, and the obtained results were based on the average values. The adsorption capacity of the zinc(II) solution was determined using Equation (1) [19]:

$$
q_{t, 1}=\frac{\left(C_{0}-C_{t}\right) V_{1} \times 65.38}{m_{1}}
$$

where $q_{t, 1}(\mathrm{mg} / \mathrm{g})$ is the adsorption capacity at time $t(\mathrm{~min}) . C_{0}$ and $C_{t, 1}(\mathrm{~mol} / \mathrm{L})$ refer to the initial zinc(II) concentration and the final concentration at time $t$ ( $\mathrm{min}$ ), respectively. $V_{1}(\mathrm{~mL})$ refers to the volume of zinc(II), and $m_{1}(\mathrm{~g})$ is the mass of the adsorbent. In the calculation $q_{t, 1}$, no losses of zinc(II) to any other mechanisms (e.g., volatilization, sorption on glassware, or degradation) were assumed.

\subsection{Desorption and Regeneration Studies}

Samples $(0.1000 \mathrm{~g})$ of zinc(II)-loaded XSBLAC were accurately weighed and transferred into 50-mL $\mathrm{HNO}_{3}$ solutions with different concentrations. Each mixture was placed in an ultrasonic cleaning machine (KS-300EI, Ninbo, China). When equilibrium was reached at a certain temperature, the suspension was centrifuged, and the desorbed zinc(II) concentrations in the solution were determined. Considering the experimental errors, three experiments were performed, and the reproducibility of the results was within $\pm 3 \%$. The desorption capacity of the zinc(II)-loaded XSBLAC was calculated according to Equation (2) [20].

$$
q_{t, 2}=\frac{C_{t, 2} V_{2} \times 65.38}{m_{2}}
$$

where $q_{t, 2}(\mathrm{mg} / \mathrm{g})$ refers to the desorption amount at time $t(\mathrm{~min}) . C_{t, 2}(\mathrm{~mol} / \mathrm{L})$ is the zinc(II) concentration in the desorbed solution at time $t(\mathrm{~min}) . V_{2}(\mathrm{~mL})$ refers to the total volume of the desorption solution, and $m_{2}(\mathrm{~g})$ is the mass of the zinc(II)-loaded XSBLAC.

Repeated batch experiments were performed to examine the reusability of XSBLAC for zinc(II) removal. The material was washed with deionized water to remove the remaining acid and dried in an oven (DZF-6210, Shanghai, China) at $120^{\circ} \mathrm{C}$ for subsequent zinc(II) adsorption. The zinc(II)-adsorption and desorption capacities were determined and analyzed. The adsorption/desorption process was performed consecutively five times.

\section{Results and Discussion}

\subsection{Adsorbent Characterization}

The specific surface area and porous system of the XSBLAC were characterized based on $\mathrm{N}_{2}$-adsorption/desorption isotherms (Micromeritics ASAP 2020, Norcross, GA, USA). XRD analysis of the powdered samples was performed using an X-ray power diffractometer with a $\mathrm{Cu}$ anode (PAN 
Alytical Co., X'pert PRO, Almelo, The Netherlands) at $40 \mathrm{kV}$ and $40 \mathrm{~mA}$ and scanning from $4^{\circ}$ to $18^{\circ}$ at $8^{\circ} / \mathrm{min}$. The morphological changes and surface analyses of the samples were conducted using SEM-EDX (HITACHI S-4800, Tokyo, Japan). FTIR spectra were recorded in KBr pellets with a FTIR spectrophotometer (Thermo Nicolet, NEXUS, TM, Waltham, MA, USA).

\subsection{Properties of XSBLAC}

$\mathrm{N}_{2}$-adsorption/desorption isotherms provide qualitative information regarding the porosity of carbonaceous adsorbents [21]. The surface physical parameters of XSBLAC obtained from its $\mathrm{N}_{2}$-adsorption/desorption isotherm are summarized in Table 1. From the results, the highest surface area $\left(688.62 \mathrm{~m}^{2} / \mathrm{g}\right)$ and total pore volume $\left(0.377 \mathrm{~cm}^{3} / \mathrm{g}\right)$ of XSBLAC were calculated using the $\mathrm{t}$-plot method. Additionally, the structure of XSBLAC was found to be loose, with many pores generated on its surface. According to the International Union of Pure and Applied Chemistry (IUPAC), the mesopore structure of XSBLAC can be supported by its average pore diameter $\left(\mathrm{D}_{p}=2.2 \mathrm{~nm}\right)$.

Table 1. Pore structure parameters of the sample studied in this work.

\begin{tabular}{|c|c|c|c|c|c|c|c|c|}
\hline Sample & $\begin{array}{c}\mathrm{S}_{B E T} \\
\left(\mathrm{~m}^{2} / \mathrm{g}\right)\end{array}$ & $\begin{array}{c}\mathrm{S}_{\text {ext }} \\
\left(\mathrm{m}^{2} / \mathrm{g}\right)\end{array}$ & $\begin{array}{c}\mathrm{S}_{\text {ext }} / \mathrm{S}_{B E T} \\
(\%)\end{array}$ & $\begin{array}{c}\mathrm{S}_{\text {mic }} \\
\left(\mathrm{m}^{2} / \mathrm{g}\right)\end{array}$ & $\begin{array}{c}\mathrm{V}_{t o t} \\
\left(\mathrm{~cm}^{3} / \mathrm{g}\right)\end{array}$ & $\begin{array}{c}\mathrm{V}_{\text {meso }} \\
\left(\mathrm{cm}^{3} / \mathrm{g}\right)\end{array}$ & $\begin{array}{c}\mathrm{V}_{\text {meso }} / \mathrm{V}_{\text {tot }} \\
(\%)\end{array}$ & $\begin{array}{c}\mathrm{D}_{p} \\
(\mathrm{~nm})\end{array}$ \\
\hline XSBLAC & 688.62 & 477.87 & 69.4 & 210.43 & 0.377 & 0.252 & 66.8 & 2.2 \\
\hline
\end{tabular}

Number of analyses: three. $S_{B E T}$-specific surface area; $S_{e x t}$-mesopore surface area, $S_{e x t} / S_{B E T}$-ratio of mesopore surface area to specific surface area, $\mathrm{S}_{\text {mic }}$ - micropore surface area, $\mathrm{V}_{\text {tot }}$ - total pore volume, $\mathrm{V}_{\text {meso }}$-mesopore volume, $\mathrm{V}_{\text {meso }} / \mathrm{V}_{\text {tot }}$-ratio of mesopore volume to total pore volume, $\mathrm{D}_{p}$ - average pore size.

Figure 1 shows the pore size distribution of XSBLAC. XSBLAC has pore sizes between $0.5 \mathrm{~nm}$ and $5.5 \mathrm{~nm}$ and displays a wide pore size distribution with a low pore volume. From Table 2, it can be seen that the mesopore surface increased remarkably. Thus, a significant amount of micropores became mesopores.

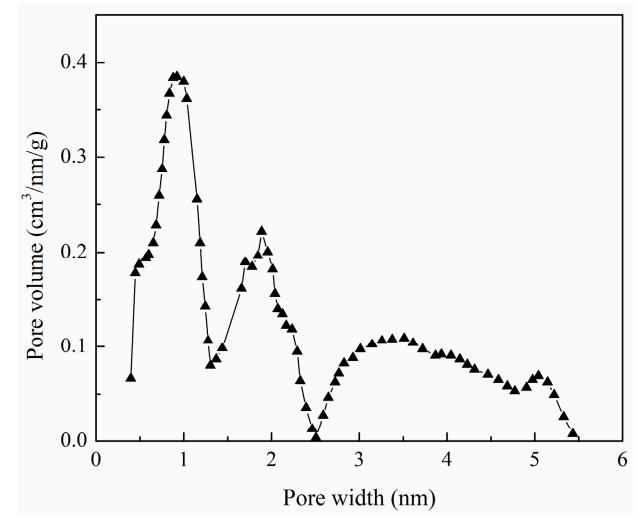

Figure 1. Pore size distribution of XSBLAC.

Table 2. Global Surface Composition as Determined by EDX Analysis.

\begin{tabular}{|c|c|c|c|c|c|c|c|}
\hline Sample & C (at \%) & O (at \%) & N (at \%) & $\mathrm{Cl}($ at $\%)$ & $\mathrm{Na}$ (at \%) & $\mathrm{O} / \mathrm{C}(\%)$ & N/C (\%) \\
\hline XSBLAC & 80.26 & 12.92 & 5.62 & 0.75 & 0.45 & 16.1 & 0.07 \\
\hline XSBL & 60.33 & 34.96 & 3.41 & 0.93 & 0.37 & 60.0 & 0.06 \\
\hline
\end{tabular}

Elemental analysis was conducted for XSBLAC and XSBL by EDX. As indicated in Table 2, the C, O, N, Cl and Na contents for XSBLAC were as follows: $80.26 \%, 12.92 \%, 5.62 \%, 0.75 \%$ and $0.45 \%$, respectively. Additionally, XSBLAC prepared from XSBL using the activating reagent $\mathrm{H}_{3} \mathrm{PO}_{4}$ during the treatment process showed a higher C content $(80.26 \%)$ than XSBL $(60.33 \%)$. 
$\mathrm{XRD}$ is an effective method for determining the morphological features of adsorbents. Figure 2 shows the XRD images of XSBL and the prepared XSBLAC. Two broad peaks are present in the XRD of the precursor, observed near $2 \theta=15^{\circ}$ and $22^{\circ}$ and attributed to the aliphatic chain of XSBLBL; this indicates that XSBLBL has a turbostratic structure and defined amorphous carbons. The XRD pattern of XSBLAC (Figure 2) shows diffraction peaks at $2 \theta=26^{\circ}, 29^{\circ}$ and $30^{\circ}$, likely because of internal etching during $\mathrm{H}_{3} \mathrm{PO}_{4}$ activation and increased numbers of complex pores in XSBLAC and shaped graphite-like microcrystalline layers, suggesting the formation of more amorphous carbon-based graphite microcrystallites [22]. Additionally, the dispersion peak $\left(2 \theta=15^{\circ}\right)$ persisted, illustrating that XSBLAC existed in a type of amorphous state.

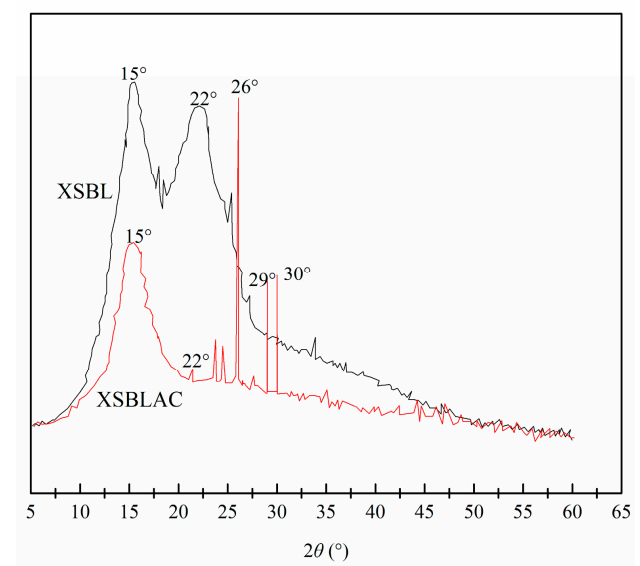

Figure 2. XRD patterns of raw XSBL and XSBLAC.

The SEM images of XSBL and XSBLAC are presented in Figure 3. This figure shows that the surface of XSBL contains many thin sheets or layers with large pores in its structure (Figure 3a). However, the AC appeared to have a well-developed coarse porous surface with irregular pores and breaks (Figure 3b). Mixtures of micropores and mesopores are present in the SEM images. This result may be attributed to the creation of pores and the substantial removal of inorganic compounds in the raw structure during activation, eventually yielding a porous surface.
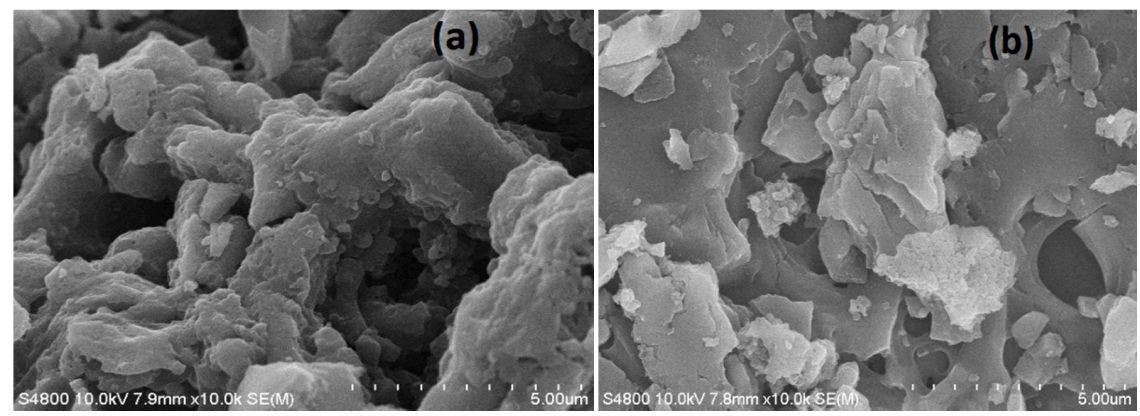

Figure 3. SEM image of raw XSBL (a) and XSBLAC (b).

\subsection{Effect of $p H$ Value on Adsorption}

The $\mathrm{pH}$ value of the zinc(II) solution is highly influential and must be considered during the adsorption process. Therefore, experiments were initially performed to optimize the $\mathrm{pH}$ value, testing values from 2.0 to 6.0, to investigate the effect of $\mathrm{pH}$ on zinc(II) removal, as shown in Figure 4 . The adsorption of zinc(II) by XSBLAC was highly $\mathrm{pH}$ dependent because the superficial charge of XSBLAC is affected by the $\mathrm{pH}$ value [23]. Indeed, the maximum adsorption capacity for zinc(II) was achieved at a $\mathrm{pH}$ value of 5.2. This result can be explained by the competition between $\mathrm{H}^{+}$and zinc(II) 
ions for activated adsorption sites on the XSBLAC surface at low $\mathrm{pH}$ levels; when the $\mathrm{pH}$ increases, the covered $\mathrm{H}^{+}$leaves the AC surface, making more adsorption sites available for zinc(II). According to the solubility product constant of zinc(II) hydrolysis $\left(\mathrm{pK}_{\mathrm{sp}}{ }^{\theta}=16.92\right)$, as the $\mathrm{pH}$ value increases, the negative charge density also increases, resulting in the production of oxygen-containing functional groups and/or ligands in XSBLAC. Therefore, all $\mathrm{pH}$ values used were below 6.0, ensuring that no hydroxide precipitation occurred during the adsorption process. Similar $\mathrm{pH}$ effects on the adsorption of heavy metals have been reported in the literature [24,25]. Hence, the optimal $\mathrm{pH}$ value for zinc(II) adsorption in this study was 5.2.

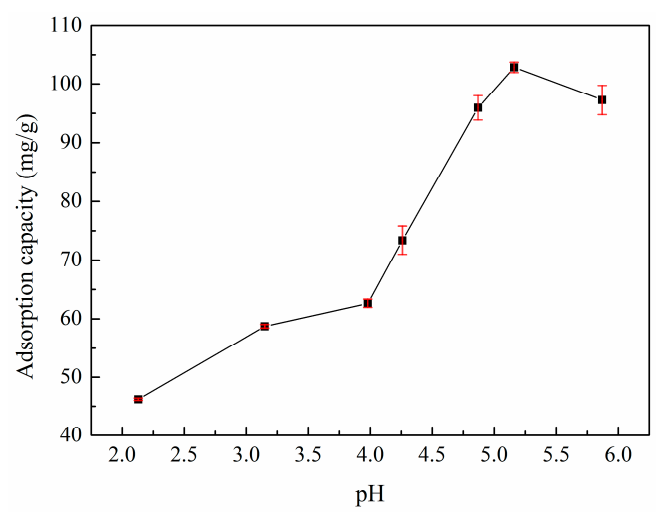

Figure 4. Effect of the $\mathrm{pH}$ values on the adsorption capacity of XSBLAC for zinc(II). (Adsorption experiments-sample dosage: $0.05 \mathrm{~g}$; initial zinc(II) concentration: $0.015 \mathrm{~mol} / \mathrm{L}$; $\mathrm{pH}$ range: 2.0-6.0; temperature: $60^{\circ} \mathrm{C}$; adsorption time: $40 \mathrm{~min}$ ).

\subsection{Effect of Temperature on Adsorption}

It is important to investigate the effect of temperature on zinc(II) adsorption for practical applications. Here, the relationship between the temperature and the adsorption capacity of XSBLAC is discussed under isothermal conditions at different temperatures, as shown in Figure 5. The adsorption capacity of XSBLAC increased as the temperature increased from 25 to $60^{\circ} \mathrm{C}$, indicating that high temperatures facilitate the adsorption of zinc(II) on the surface of XSBLAC. This result can be attributed to the fact that high temperature may produce a loosening effect within the structure and activate the functional groups of XSBLAC, leading to further adsorption of zinc(II) ions into the structure of AC. However, at temperatures above $60{ }^{\circ} \mathrm{C}$, the adsorption capacity decreased, accounting for the endothermic behavior of the adsorption process. These results can be attributed to the chemical adsorption action between XSBLAC and zinc(II). In the following experiments, a pH of 5.2 was selected as the optimum $\mathrm{pH}$ value.

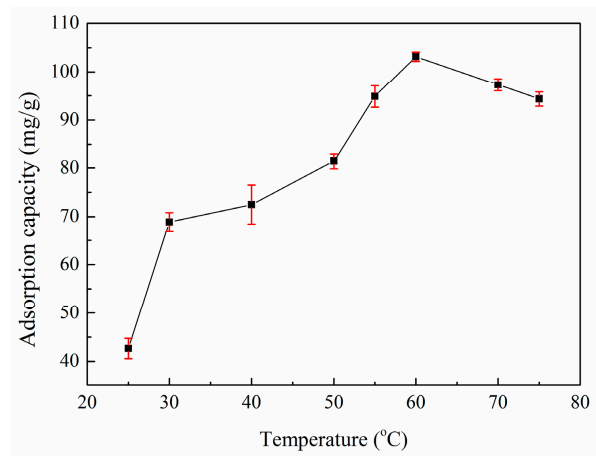

Figure 5. Effect of temperature on the adsorption capacity of XSBLAC for zinc(II). (Adsorption experiments-sample dosage: $0.05 \mathrm{~g}$; initial zinc(II) concentration: $0.015 \mathrm{~mol} / \mathrm{L}$; $\mathrm{pH}$ range: 5.16; temperature: $25-75{ }^{\circ} \mathrm{C}$; adsorption time: $40 \mathrm{~min}$ ). 


\subsection{Adsorption Kinetics}

The effect of adsorption time on the removal of zinc(II) by XSBLAC was investigated, and the results are shown in Figure 6. The adsorption capacity of XSBLAC greatly increased from 10 to $40 \mathrm{~min}$ until equilibrium and then remained nearly stable as the adsorption time increased further. This behavior may be why zinc(II) ions first adsorbed on the surface's unsaturated activated functional sites, subsequently diffused into the XSBLAC's micropores, and finally adsorbed on functional sites, thereby saturating the material's mesopores and reaching adsorption equilibrium. Therefore, an adsorption time of $40 \mathrm{~min}$ was chosen as the optimal equilibrium time for the adsorption of zinc(II) on XSBLAC under the experimental conditions.

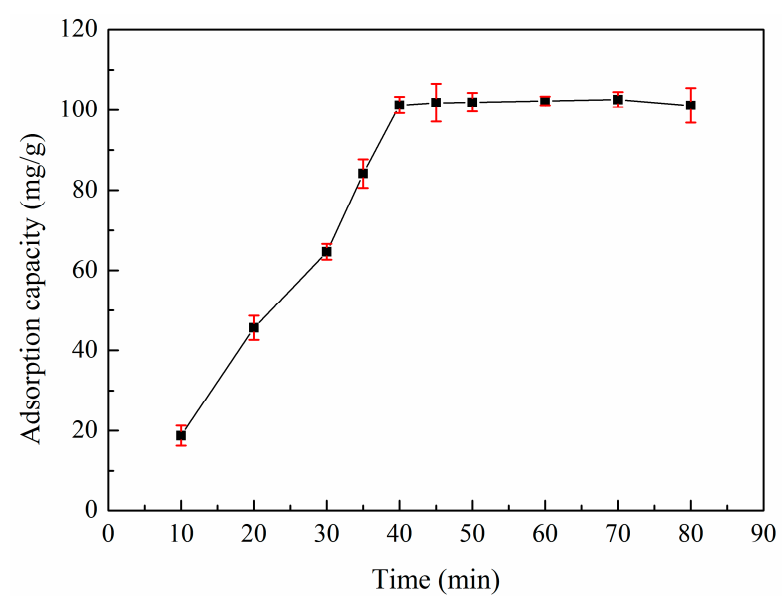

Figure 6. Effect of time on the adsorption capacity of XSBLAC for zinc(II). (Adsorption experimentssample dosage: $0.05 \mathrm{~g}$; initial zinc(II) concentration: $0.015 \mathrm{~mol} / \mathrm{L} ; \mathrm{pH}$ value: 5.16 ; temperature: $60^{\circ} \mathrm{C}$; adsorption time: $10-80 \mathrm{~min})$.

To study the potential rate-controlling steps of adsorption, pseudo-first-order, pseudo-second-order, intraparticle diffusion, Elovich and Bangham kinetic models are generally used to fit the experimental data, which are described as Equations (3)-(7) [26-28].

$$
\begin{gathered}
\lg \left(q_{e}-q_{t, 1}\right)=\lg q_{e}-\frac{k_{1} t}{2.303} \\
\frac{t}{q_{t, 1}}=\frac{1}{k_{2} q_{e}^{2}}+\frac{t}{q_{e}} \\
q_{t}=k_{i} t^{0.5} \\
q_{t}=\frac{1}{\beta} \ln (\alpha \beta)+\frac{1}{\beta} \ln t \\
\log q_{t}=\log k_{r}+\frac{1}{m} \log t
\end{gathered}
$$

where $q_{e}$ and $q_{t, 1}$ are the amounts of zinc(II) ions adsorbed (mg/g) at equilibrium and at time $t$ (min), respectively; $k_{1}\left(\mathrm{~min}^{-1}\right)$ is the pseudo-first-order rate constant; $k_{2}\left[\mathrm{~g} \cdot(\mathrm{mg} / \mathrm{min})^{-1}\right]$ is the rate constant of the pseudo-second-order adsorption kinetic equation; $k_{i}\left[\mathrm{mg} \cdot\left(\mathrm{g} \cdot \mathrm{min}^{0.5}\right)^{-1}\right]$ is an intraparticle diffusion rate constant; $\alpha\left[\mathrm{mg} \cdot(\mathrm{g} \cdot \mathrm{min})^{-1}\right]$ is an initial adsorption rate; and $\beta(\mathrm{g} / \mathrm{mg})$ is related to the surface coverage and activation energy for chemisorption; $k_{r}\left[\mathrm{mg} \cdot \mathrm{g}^{-1} \cdot \mathrm{min}^{-1}\right]$ is the rate constant of adsorption; $1 / m$ is an indicator of the adsorption intensity.

The fits of these five models were checked by each linear plot of $\ln \left(q_{e}-q_{t}\right)$ versus $t$ (Figure 7a), $\left(t / q_{t}\right)$ versus $t$ (Figure $\left.7 \mathrm{~b}\right), q_{t}$ versus $t^{0.5}$ (Figure $7 \mathrm{c}$ ), $q_{t}$ versus $\ln t$ (Figure $7 \mathrm{~d}$ ), and $\ln q_{t}$ verse $\ln t$ (Figure $7 \mathrm{e}$ ), respectively. The $R^{2}$ and constant values for the five adsorption kinetic models were 
calculated and are given in Table 3. According to the calculated kinetic model parameters in Table 3 and from comparing the experimental equilibrium adsorption capacity, it was clearly found that the calculated $q_{e}$ value $(103.82 \mathrm{mg} / \mathrm{g})$ agreed with the experimental data $(110.48 \mathrm{mg} / \mathrm{g})$, and the pseudo-second-order model produced a good fit based on the value of $R^{2}(0.9416)$, indicating that the pseudo-second-order kinetics model can reflect the adsorption process of XSBLAC. Therefore, it is obvious that chemical adsorption should be the rate limiting step of the adsorption of zinc(II) ions onto the prepared activated carbon XSBLAC.
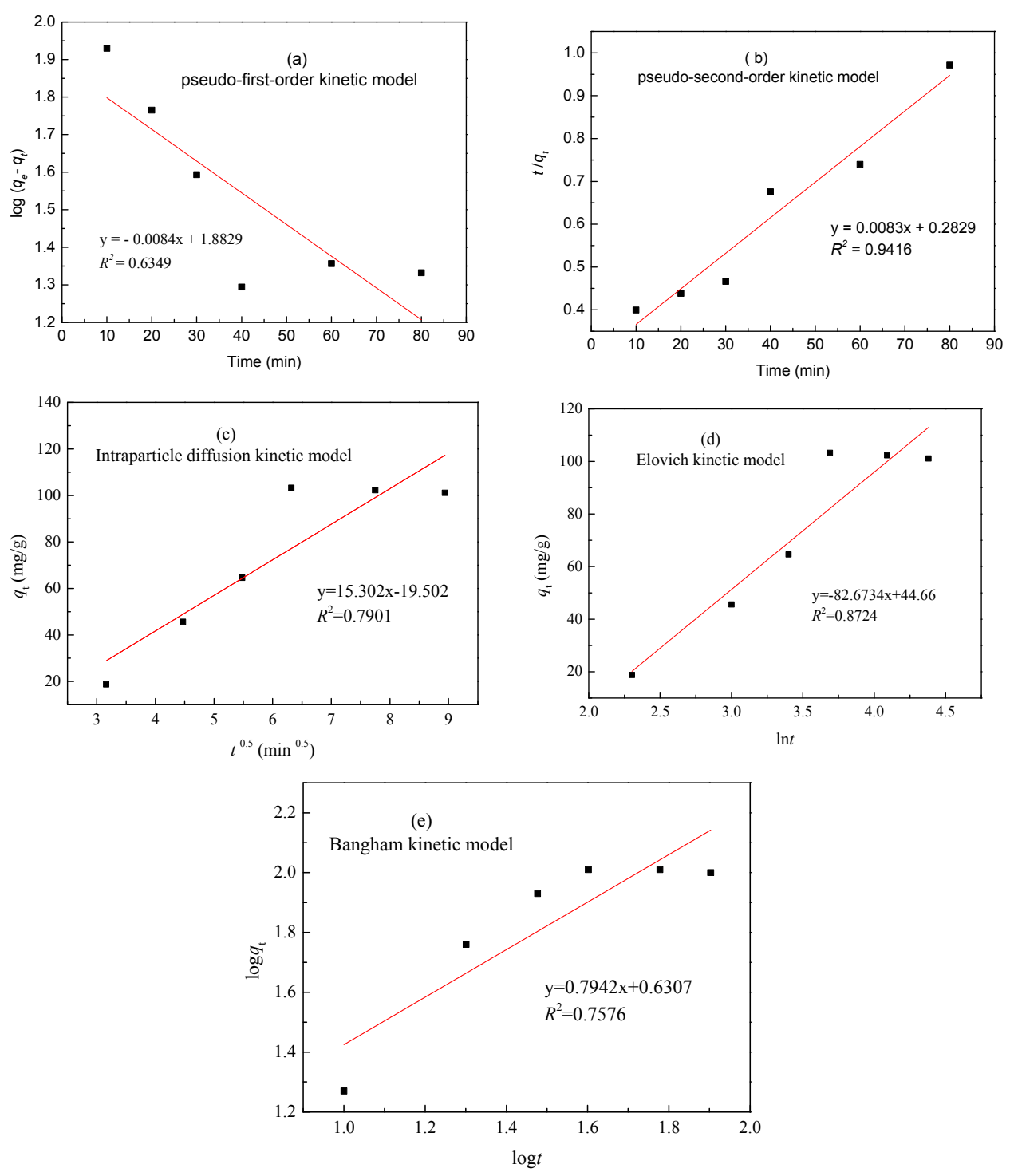

Figure 7. Pseudo-first-order (a); pseudo-second-order (b); intraparticle diffusion (c); Elovich (d) and Bangham (e) adsorption kinetic equations fitting curves of experimental data. (Adsorption experiments-sample dosage: $0.05 \mathrm{~g}$; initial zinc(II) concentration: $0.015 \mathrm{~mol} / \mathrm{L}$; $\mathrm{pH}$ value: 5.16; temperature: $60^{\circ} \mathrm{C}$ ). 
Table 3. Comparison of the estimated adsorption rate constants, $q_{e}$, and the correlation coefficients of the five kinetic models.

\begin{tabular}{|c|c|c|c|c|c|c|c|c|c|c|c|c|}
\hline \multirow{4}{*}{$\begin{array}{l}\text { Metal } \\
\text { Zinc(II) }\end{array}$} & \multirow{3}{*}{$\begin{array}{c}\begin{array}{c}q_{e}(\exp ) \\
(\mathrm{mg} / \mathrm{g})\end{array} \\
103.82\end{array}$} & \multirow{3}{*}{$\begin{array}{c}\text { Parameters } \\
R^{2} \\
\text { Constants }\end{array}$} & \multicolumn{2}{|c|}{ Pseudo-First-Order } & \multicolumn{2}{|c|}{ Pseudo-First-Order } & \multicolumn{2}{|c|}{ Intraparticle Diffusion } & & \multirow{2}{*}{$\begin{array}{c}\text { Elovich } \\
0.8724\end{array}$} & \multicolumn{2}{|c|}{ Bangham Model } \\
\hline & & & & 0.6349 & & 0.9416 & & 0.7901 & & & 0.757 & \\
\hline & & & $k_{1}$ & $0.01329 \mathrm{~min}^{-1}$ & $K_{2}$ & $\begin{array}{c}2.764 \times 10^{-4} \\
\min ^{-1}\end{array}$ & $k_{i}$ & $\begin{array}{c}15.302 \\
\mathrm{mg} /\left(\mathrm{g} \min ^{0.5}\right)\end{array}$ & $\alpha$ & $\begin{array}{c}11.2501 \\
\mathrm{mg} /(\mathrm{g} \min )\end{array}$ & $\begin{array}{c}K_{r} \\
\left(\mathrm{mg} \cdot \mathrm{g}^{-1} \cdot \min ^{-1}\right)\end{array}$ & 0.7942 \\
\hline & & & $q_{e}(\mathrm{cal})$ & $76.36 \mathrm{mg} / \mathrm{g}$ & $q_{e}(\mathrm{cal})$ & $110.48 \mathrm{mg} / \mathrm{g}$ & & & $\beta$ & $0.01327 \mathrm{~g} / \mathrm{mg}$ & $m$ & 0.1004 \\
\hline
\end{tabular}




\subsection{Adsorption Isotherms}

The effect of the initial zinc(II) concentration on the adsorption capacity of XSBLAC is shown in Figure 8. The initial concentration of zinc(II) substantially influenced the adsorption capacity, which increased sharply as the initial zinc(II) concentration increased until equilibrium but hardly increased as the zinc(II) concentration was increased further. Thus, the zinc(II)-removal process probably involves an interaction between the activated sites on XSBLAC and zinc(II), which may result from the increase in initial zinc(II) concentration accelerating the bonding of zinc(II) onto XSBLAC, thereby increasing the driving force underlying the concentration gradient [29]. Increasing the zinc(II) concentration further did not increase the adsorption capacity because the activated sites on XSBLAC were saturated. An initial zinc(II) concentration of $0.015 \mathrm{~mol} / \mathrm{L}$ was used to ensure that the adsorption equilibrium would be reached.

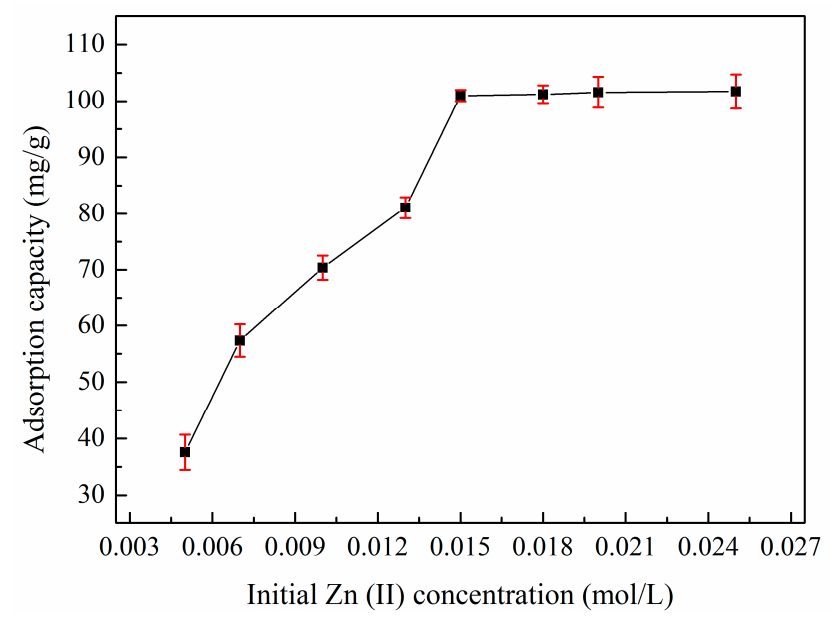

Figure 8. Effect of initial zinc(II) concentration on the adsorption capacity of XSBLAC for zinc(II). (Adsorption experiments-sample dosage: $0.05 \mathrm{~g}$; initial zinc(II) concentration: $0.005-0.025 \mathrm{~mol} / \mathrm{L}$; $\mathrm{pH}$ value: 5.16 ; temperature: $60{ }^{\circ} \mathrm{C}$; adsorption time: $40 \mathrm{~min}$ ).

Adsorption isotherm models are commonly used to describe the characteristics of an adsorption process between solid and liquid phases when adsorption equilibrium is reached. The linear forms of the Langmuir and Freundlich isotherms are represented, respectively, by Equations (8) and (9) [30]:

$$
\begin{gathered}
\frac{C_{e}}{q_{e}}=\frac{1}{b q_{m}}+\frac{C_{e}}{q_{m}} \\
\ln q_{e}=\ln k_{f}+\frac{1}{n} \ln C_{e}
\end{gathered}
$$

where $C_{e}$ is the concentration of zinc(II) at equilibrium (mol/L), $q_{e}$ is the amount adsorbed (mg/g), $q_{m}$ is the complete monolayer adsorption capacity $(\mathrm{mg} / \mathrm{g}), b$ is the Langmuir constant related to the adsorption capacity $(\mathrm{L} / \mathrm{mg})$, and $n$ and $k_{f}$ are the Freundlich constants.

A plot of $C_{e} / q_{t}$ versus $C_{e}$ is shown in Figure $9 \mathrm{a}$, and the Langmuir constants were calculated using the slopes and intercepts listed in Table 4. Similarly, a plot of $\ln q_{e}$ versus $\ln C_{e}$ (Figure $9 \mathrm{~b}$ ) was used to evaluate the Freundlich constants, which are also presented in Table 3. From the correlation coefficient $\left(R^{2}\right)$ values in Table $4, R^{2}$ value of $0.9793\left(p\left(1.327 \times 10^{-4}\right)<0.01\right)$ for the Langmuir isotherm adsorption model is higher than that for the Freundlich model of $R^{2}$ value of $0.7683(p(0.0026)<0.01)$, and there was no significant in the adsorption of zinc(II) ions. The experimental data for the adsorption process had better correlation coefficients values and better fits with the Langmuir isotherm model than with the Freundlich model (Figure 9). Therefore, the adsorption process of zinc(II) onto XSBLAC was found to follow the Langmuir isotherm model $\left(R^{2}=0.9793, p<0.01\right)$, with a maximum monolayer adsorption 
capacity of $103.82 \mathrm{mg} / \mathrm{g}$. This result revealed the anchoring of zinc(II) to the abundant functional groups on XSBLAC with the formation of monolayer surface coverage that was homogenous in nature. Moreover, the characteristics of the Langmuir equation can be explained in terms of the equilibrium parameter $\left(R_{L}\right)$ according to Equation (10) [31]:

$$
R_{L}=\frac{1}{1+b C_{0}}
$$

where $b$ is the Langmuir constant $(\mathrm{L} / \mathrm{mg})$, and $C_{0}$ is the initial concentration $(\mathrm{mol} / \mathrm{L})$. The value of $R_{L}$ describes the nature of the adsorption: irreversible $\left(R_{L}=0\right)$; favorable $\left(0<R_{L}<1\right)$; linear $\left(R_{L}=1\right)$; unfavorable $\left(R_{L}>1\right)$ [32]. In this study, the $R_{L}$ value over the given initial zinc(II) concentration range was calculated (0.1362) and is shown in Table 4, confirming that XSBLAC was favorable for zinc(II) adsorption under the adsorption conditions employed.
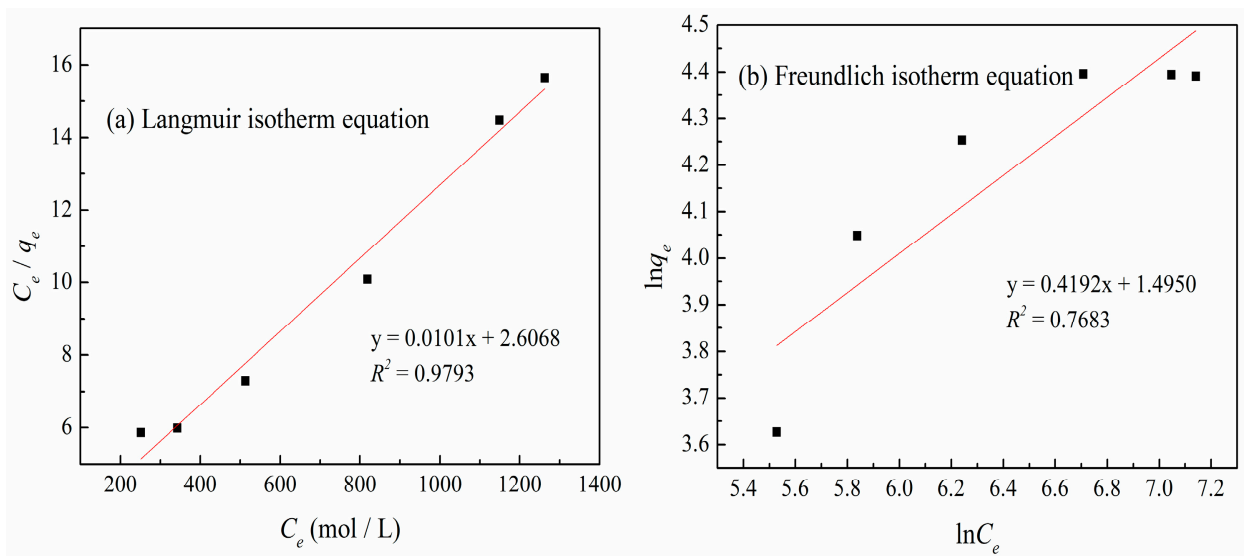

Figure 9. Langmuir (a) and Freundlich (b) isotherm equations fitting curves of the experimental data. (Adsorption experiments-sample dosage: $0.05 \mathrm{~g}$; $\mathrm{pH}$ value: 5.16 ; temperature: $60^{\circ} \mathrm{C}$; adsorption time: $40 \mathrm{~min})$.

Table 4. Adsorption equilibrium constants obtained from the Langmuir and Freundlich isotherms for zinc(II) adsorption onto XSBLAC. (Adsorption experiment sample dosage: $0.05 \mathrm{~g}$; $\mathrm{pH}$ value: 5.2; temperature: $60^{\circ} \mathrm{C}$; adsorption time: $40 \mathrm{~min}$ ).

\begin{tabular}{cccccccccc}
\hline \multirow{2}{*}{$\begin{array}{c}\boldsymbol{q}_{\boldsymbol{m}} \\
\mathbf{m g} / \mathbf{g})\end{array}$} & \multicolumn{4}{c}{ Langmuir Isotherm Equation } & \multicolumn{4}{c}{ Freundlich Isotherm Equation } \\
\cline { 2 - 10 } & $\boldsymbol{q}_{\boldsymbol{e}} \mathbf{( \mathbf { m g } / \mathbf { g } )}$ & $\boldsymbol{b} \mathbf{( \mathbf { m g } / \mathrm { L } )}$ & $\boldsymbol{R}_{\boldsymbol{L}}$ & $\mathbf{R}^{\mathbf{2}}$ & $\boldsymbol{p}$ & $\mathbf{1 / n}$ & $\boldsymbol{k}_{\boldsymbol{f}}(\mathbf{m g} / \mathrm{L})$ & $\boldsymbol{R}^{\mathbf{2}}$ & $\boldsymbol{p}$ \\
\hline 103.82 & 100.76 & 0.0039 & 0.1362 & 0.9793 & $1.327 \times 10^{-4}$ & 0.4133 & 4.614 & 0.7683 & 0.0026 \\
\hline
\end{tabular}

Thermodynamic parameters were calculated to determine which process would occur spontaneously. The variation of the thermodynamic parameters $\left(\Delta H^{0}, \Delta S^{0}\right.$ and $\left.\Delta G^{0}\right)$ should provide insight into the mechanism and adsorption of an isolated system [33]. The enthalpy $\left(\Delta H^{0}\right)$ and entropy $\left(\Delta S^{0}\right)$ values can be calculated from the slope and intercept of the plot of $\ln K$ vs. $1 / T$ according to Equation (11) [34]:

$$
\ln K=\frac{\Delta S^{0}}{R}-\frac{\Delta H^{0}}{R T}
$$

where $R(8.314 \mathrm{~J} / \mathrm{mol} \cdot \mathrm{K})$ is the universal gas constant, and $T(\mathrm{~K})$ is the adsorption temperature in Kelvin. The Gibb's free energy change $\left(\Delta G^{0}\right)$ was calculated from the Langmuir equilibrium constant in units of liters per mole according to Equation (12) [35]:

$$
\Delta G^{0}=-R T \ln K
$$


where $K(\mathrm{~L} / \mathrm{mol})$ is from the Langmuir equation and has units of liters per mole. The Gibb's free energy $\left(\Delta G^{0}\right)$ was $-19.91 \mathrm{KJ} / \mathrm{mol}$ at $60{ }^{\circ} \mathrm{C}$, and its negative values verified the thermodynamic feasibility and spontaneity of the adsorption process under the applied experimental conditions. $\Delta H^{0}$ was $59.68 \mathrm{KJ} / \mathrm{mol}$, which further confirmed the endothermic behavior of XSBLAC. The positive value of $\Delta S^{0}(0.239 \mathrm{~J} / \mathrm{K} / \mathrm{mol})$ may be attributed to the affinity of XSBLAC for zinc(II) and the increasing randomness at the solid-liquid interface. It can be concluded that the adsorption of XSBLAC was an endothermic and spontaneous process based on the thermodynamic data of the adsorption isotherm.

Many thermodynamic properties of polymer-solutions such as solubilities, swelling equilibria, and the colligative properties can be expressed in terms of the polymer-solvent interaction parameter. Generally, the Flory-Huggins interaction parameter describes the degree of segregation in polymer blends and block copolymers, which is typically expressed as a function of temperature, $T$. To establish a relationship between $\chi$ and $T$, we follow the approach of Rana et al. and calculate using Equations (13)-(15) [36-38].

$$
\begin{gathered}
\Delta G^{0}=\Delta H^{0}-T \Delta S^{0} \\
\Delta G^{0}=R T\left(\frac{\phi_{1}}{N_{1}} \ln \phi_{1}+\frac{\phi_{2}}{N_{2}} \ln \phi_{2}+\chi \phi_{1} \phi_{2}\right) \\
\chi=\frac{\alpha}{T}+\beta
\end{gathered}
$$

where $\phi_{1}$ is the volume fraction of XSBLAC particles, $\phi_{2}$ is the volume fraction of zinc(II), $N_{1}$ is the molecular volume of XSBLAC particles, $N_{2}$ is the molecular volume of zinc(II), $\chi$ is the F-H interaction parameter, $T$ is the temperature, $\alpha$ and $\beta$ are parameters for enthalpic and entropic contributions to $\chi$, respectively.

$\chi$ has been found to decrease with temperature with a dependence that is approximately linear with, but not proportional to $1 / T$ for many systems. In this work, the $\chi$ with a value of 0.34 is extrapolated and obtained, which is representative of a miscible system and an exothermic heat of XSBLAC and zinc(II). It should be noted that the $\chi$ value is very close to zero, suggesting more favorable mixing at the temperature of $60^{\circ} \mathrm{C}$, which more conducive to the adsorption process between XSBLAC and zinc(II).

\subsection{Desorption and Regeneration}

Performing desorption and regeneration studies of spent adsorbents can produce various benefits, such as lowering the cost associated with the adsorption process, recovering valuable zinc(II), and reducing possible secondary pollution. Thus, a desorbing solution must be inexpensive, effective, and non-polluting. Batches of desorption and regeneration experiments were conducted in the present work using $\mathrm{HCl}, \mathrm{H}_{2} \mathrm{SO}_{4}, \mathrm{HNO}_{3}, \mathrm{H}_{3} \mathrm{PO}_{4}, \mathrm{C}_{2} \mathrm{H}_{5} \mathrm{OH}$ and $\mathrm{NaOH}$ as the desorbing eluent to test their effects on desorption (Figure 10a). Figure 10a clearly shows that $\mathrm{NaOH}$ is almost ineffective at releasing bonded zinc(II) ions from XSBLAC. The desorption efficiency of $\mathrm{C}_{2} \mathrm{H}_{5} \mathrm{OH}$ was slightly higher than that of $\mathrm{NaOH}$ but still showed weak potential for detaching zinc(II) compared with acid solutions. Among the four acidic desorption solutions, $\mathrm{HCl}, \mathrm{H}_{2} \mathrm{SO}_{4}, \mathrm{HNO}_{3}$ and $\mathrm{H}_{3} \mathrm{PO}_{4}$, and $\mathrm{HNO}_{3}$ were found to be good reagents for the regeneration of zinc(II)-loaded XSBLAC. This result was expected because under acidic conditions, electrostatic interactions occurred on the surface of XSBLAC, which was became protonated by $\mathrm{H}^{+}$ions, thereby allowing the desorption of positively charged zinc(II). The desorption efficiency of $\mathrm{HNO}_{3}$ was better than those of $\mathrm{HCl}, \mathrm{H}_{2} \mathrm{SO}_{4}$ and $\mathrm{H}_{3} \mathrm{PO}_{4}$ for zinc(II) removal from XSBLAC.

The effect of using $\mathrm{HNO}_{3}$ solution as a desorption reagent on the desorption capacity of zinc(II)-loaded XSBLAC, including the $\mathrm{HNO}_{3}$ concentration, desorption temperature and ultrasonic desorption time, is discussed in detail. The desorption capacity initially increased and then decreased with increasing $\mathrm{HNO}_{3}$ concentration (Figure 10b), possibly because the accumulated $\mathrm{H}^{+}$concentration increases the concentration gradients of zinc(II) and $\mathrm{H}^{+}$, which constitute the driving force underlying ion exchange and favoring the desorption process [39]. The desorption capacity first increased and then slightly decreased with increasing desorption temperature (Figure 10c); this behavior is likely 
attributable to the higher temperature, which may enhance the efficiency and activity of the adsorption sites of XSBLAC until equilibrium is reached [40]. The desorption capacity initially increased and then remained constant with increasing ultrasonic desorption time (Figure 10d), consistent with the production of holes, and then reached saturation under ultrasonic conditions [41]. Subsequently, the effect of regenerating and reusing the XSBLAC for five consecutive adsorption/desorption cycles of zinc(II) was investigated, and the results are listed in Table 5. The zinc(II)-adsorption capacity decreased only slightly with increasing reuse times, and the desorbed XSBLAC was effective for re-adsorption in the fourth cycle under the experimental conditions used. Thus, XSBLAC presents excellent reusability and can be employed as a suitable reagent for the removal of zinc(II) from wastewater numerous times.
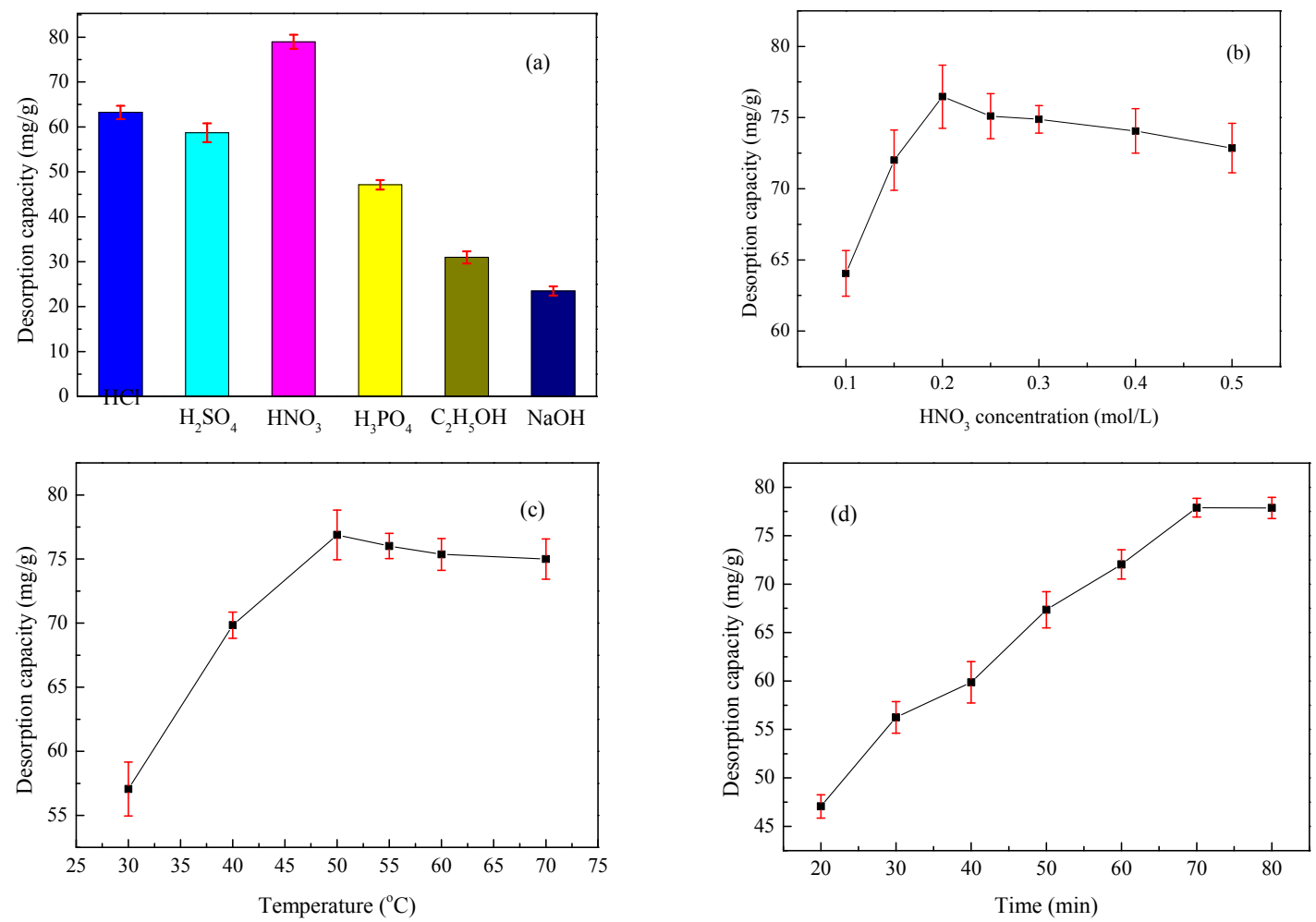

Figure 10. Effects of various desorption reagents (a); $\mathrm{HNO}_{3}$ concentration (b); temperature (c) and time (d) on desorption capacity of XSBLAC for zinc(II).

Table 5. Adsorption/desorption capacities of zinc(II) on XSBLAC after five consecutive cycles.

\begin{tabular}{cccccc}
\hline Recycle Times & 1st & 2nd & 3rd & 4th & 5th \\
\hline Adsorption capacity (mg/g) & 103.82 & 94.06 & 92.62 & 80.83 & 42.44 \\
Desorption capacity (mg/g) & 78.52 & 73.31 & 71.05 & 60.76 & 19.17 \\
\hline
\end{tabular}

\subsection{Adsorption Mechanism}

The surface functional groups of the adsorbent highly influence its characteristics and adsorption capabilities. The FTIR spectra of XSBLAC after the adsorption and desorption of zinc(II) are presented in Figure 11. The absorbance bands of XSBLAC (Figure 11a) were found to include a broad overlapping band at 3200-3500 $\mathrm{cm}^{-1}$, with a peak at $3422 \mathrm{~cm}^{-1}$, which can be attributed to the O-H stretching of the hydroxyl groups and intermolecular hydrogen bonds. The position and asymmetry of this band implied the presence of strong hydrogen bonds. This peak shifted to lower wave number $3420 \mathrm{~cm}^{-1}$ and weakened after the adsorption of zinc(II) (Figure 11b), indicating that the O-H and the corresponding hydrogen bonds of XSBLAC were broken to react with zinc(II). The bands at 2452 and 
$2350 \mathrm{~cm}^{-1}$ were related to the $\mathrm{C}-\mathrm{H}$ stretching of methyl groups (Figure 11a) and nearly disappeared after adsorption of zinc(II) ions (Figure 11b). The intensity of the peak at approximately $1670 \mathrm{~cm}^{-1}$ (Figure 11a) revealed the characteristics of the $\mathrm{C}=\mathrm{O}$ stretching in the carboxylic organic acid groups, which were shifted to lowered wave number and greatly reduced after zinc(II) adsorption (Figure 11b). Logically, the peaks appearing at 1184 and $1127 \mathrm{~cm}^{-1}$ (Figure 11a) were assigned to $\mathrm{P}=\mathrm{O}$ groups because $\mathrm{H}_{3} \mathrm{PO}_{4}$ was used as the activating agent, leading to the formation of phosphate acid esters [42]. Furthermore, the band at approximately $1043 \mathrm{~cm}^{-1}$ (Figure 11a) was ascribed to the C-O stretching in saturated aliphatic groups, and $-\mathrm{C}-\mathrm{O}$ and $-\mathrm{O}-\mathrm{C}=\mathrm{O}$ stretching of the carboxyl groups, which was broadened and reduced after adsorption of zinc(II) (Figure 11b) [43]. Adsorption bands that occurred at approximately 968,815 , and $764 \mathrm{~cm}^{-1}$ were related to $\mathrm{C}-\mathrm{H}$ groups of the benzene ring and aromatic alcohols, and the peak at $560 \mathrm{~cm}^{-1}$ may be assigned to the outer-of-plane bending of $\mathrm{C}-\mathrm{O}$ bonds of alcohols; these peaks shrank after adsorption (Figure 11b) [44]. In addition, the FTIR spectrum of XSBLAC after the desorption of zinc(II) ions (Figure 11c) almost coincided with that of the original XSBLAC (Figure 11a). These changes in the absorption peaks indicated that the activated sites on the surface of XSBLAC contained hydroxyl and carboxylic functional groups, and the free carboxyl groups became carboxylates, which suggested during the adsorption reaction between zinc(II) ions and XSBLAC. Generally, ion exchange occurred, and chemical bonds were formed between zinc(II) and the $-\mathrm{OH},-\mathrm{C}=\mathrm{O}$, and $-\mathrm{O}-\mathrm{C}=\mathrm{O}$ groups of XSBLAC. Above all, FTIR spectra comparison showed that XSBL-AC may be applicable as an effective renewable adsorber of zinc(II) from wastewater.

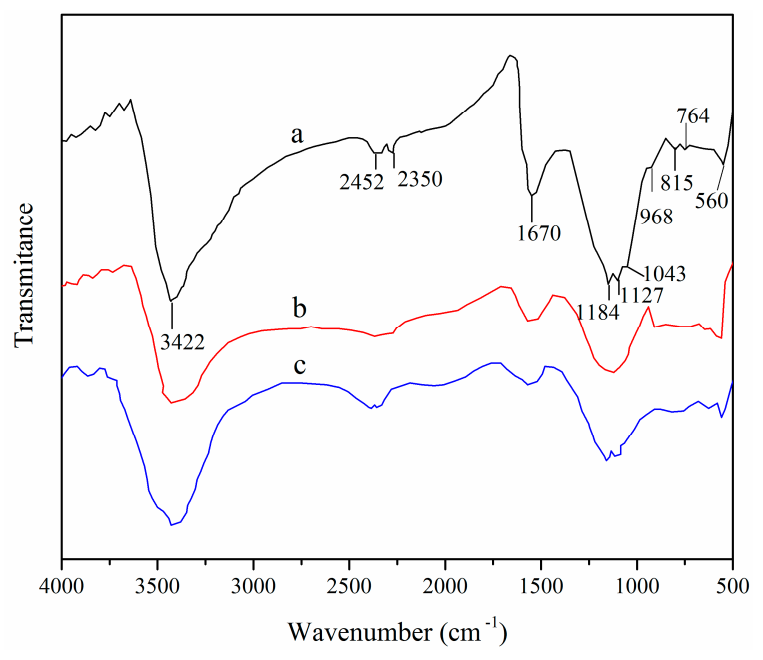

Figure 11. FTIR spectra of XSBLAC (a); after adsorption (b) and after desorption (c) of zinc(II).

The surface morphologies of XSBLAC before and after zinc(II) adsorption are presented in Figure 12. From Figure 12a, it can be seen that the surface of XSBLAC contained many thin sheets and layers of irregular shapes and sizes with steps and broken edges, which may be an appropriate structure for zinc(II) adsorption. After the adsorption process, the XSBLAC surface was evenly packed with zinc(II) ions and the sheet-stacking structure disappeared (Figure 12b). Distributions of the protruding tips are not evenly spread, hinting that zinc(II) was adsorbed on the activated sites which mainly existed on the protruding tips of the microporous surface, and only selected functional groups are involved in the adsorption of zinc(II) ions. These results indicated that the adsorption of XSBLAC toward zinc(II) may be a chemical interaction, supporting the previously proposed adsorption mechanism. 

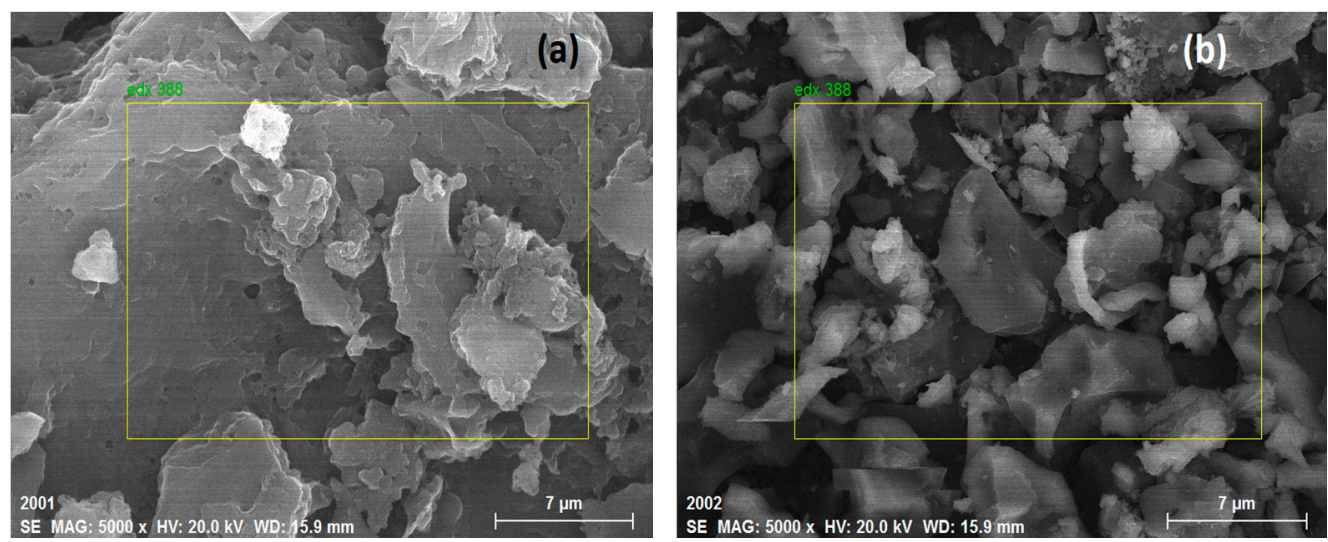

Figure 12. SEM images of XSBLAC before (a) and after (b) adsorption of zinc(II).

The EDX is an analytical technique used for elemental analysis. EDX analysis of XSBLAC was performed to confirm existence of zinc(II) on zinc(II)-loaded XSBLAC. The elemental compositions of XSBLAC before and after zinc(II) adsorption were analyzed, and the results are presented in Figure 13. The EDX results of XSBLAC (Figure 13a) revealed the presence of C (80.26\%), O (12.92\%), N (5.62\%), $\mathrm{Cl}(0.75 \%)$ and $\mathrm{Na}(0.45 \%)$. After zinc(II) adsorption, two new peaks of zinc(II) were found in the EDX spectrum (Figure 12b); the at \% values of the zinc(II)-loaded XSBLAC were C $(77.76 \%), \mathrm{O}(10.73 \%), \mathrm{N}$ $(5.21 \%), \mathrm{Zn}(5.88 \%), \mathrm{Cl}(0.31 \%)$ and $\mathrm{Na}(0.11 \%)$. This result verified the presence of zinc(II) ions on the surface of XSBLAC after adsorption [45]. From the SEM-EDX results, it was concluded that XSBLAC could to adsorb zinc(II) from wastewater.
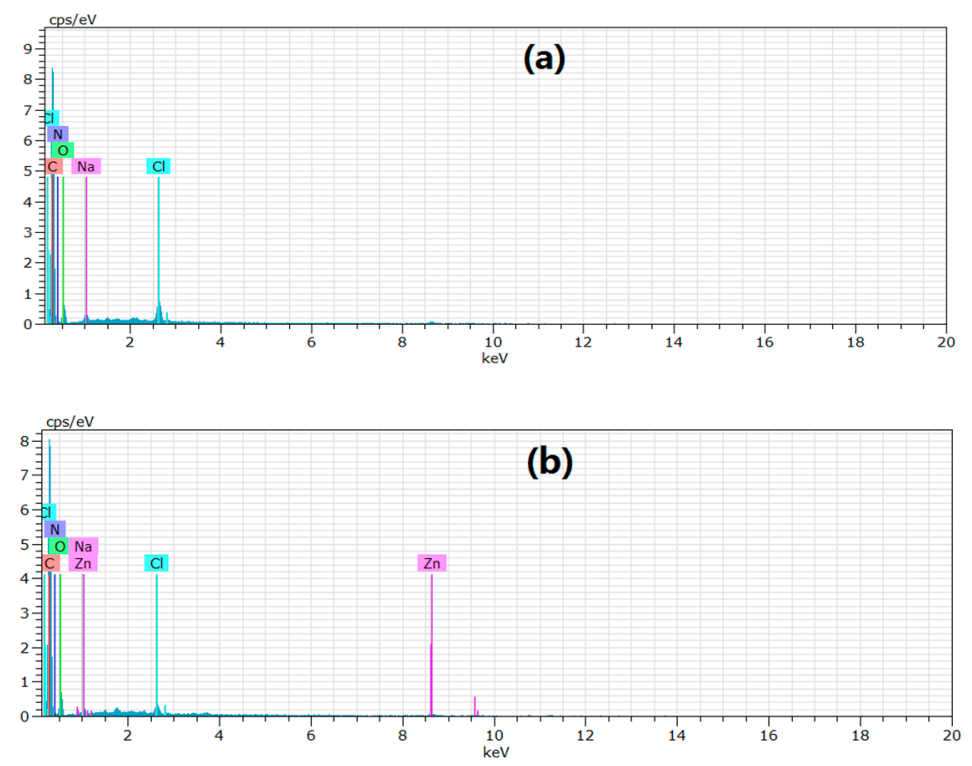

Figure 13. EDX analysis of XSBLAC before (a) and after (b) adsorption zinc(II).

\subsection{Comparison with Previously Reported Data for Zinc(II) Adsorption}

Table 6 shows various adsorbents that have been applied in removing zinc(II) from aqueous solution, as reported in the previous literature, for comparison purposes. Through the comparative study, we can conclude that XSBLAC is one of the most powerful adsorbents prepared for industrial wastewater treatment. 
Table 6. Comparison of $q_{\max }$ for removal of zinc(II) by various adsorbents.

\begin{tabular}{ccc}
\hline Adsorbent Material & $q_{\max }(\mathbf{m g} / \mathbf{g})$ & Reference \\
\hline XSBLAC & 103.82 & This study \\
SWCNTs & 43.66 & {$[46]$} \\
MWCNTs & 32.68 & {$[46]$} \\
PAV & 13.04 & {$[46]$} \\
Sil/PE1/GA0.5 & 32.79 & {$[47]$} \\
Frontinalis antipyretica & 14.7 & {$[48]$} \\
PWS & 82 & {$[49]$} \\
Coir & 8.6 & {$[50]$} \\
\hline
\end{tabular}

\section{Conclusions}

In summary, a novel XSBLAC was successfully prepared and employed in solution for the removal of zinc(II) ions. The investigated adsorbent was inexpensive and eco-friendly. The experimental results showed that XSBLAC has excellent adsorption capacity for zinc(II) ions from aqueous solutions, which can be attributed to its high surface area $\left(688.62 \mathrm{~m}^{2} / \mathrm{g}\right)$, total pore volume $\left(0.377 \mathrm{~cm}^{3} / \mathrm{g}\right)$, O-containing functional activated groups, and electrostatic attraction to zinc(II). Batches of adsorption tests were conducted, and the experimental values obtained were found to be in good agreement with those predicted by the models. The adsorption process was well described by the pseudo-second-order model. The adsorption equilibrium data of zinc(II) on the surface of XSBLAC was suitable for the Langmuir model (maximum monolayer adsorption capacity of $103.82 \mathrm{mg} / \mathrm{g}$ ), and thermodynamic studies revealed the spontaneous and endothermic nature of the adsorption process. XSBLAC was shown to exhibit an effective desorption performance when washed with an $\mathrm{HNO}_{3}$ solution as an eluent, and the maximum desorption capacity obtained was $78.52 \mathrm{mg} / \mathrm{g}$. Additionally, the adsorption capacity after regeneration was even higher until four adsorption/desorption cycles. Furthermore, FTIR and SEM/EDX results demonstrated that zinc(II) ions were mainly adsorbed by selected activated groups in coarse mesopores on the XSBLAC surface; the adsorption mechanism was likely a chemisorption process. Overall, the XSBLAC prepared in this study has potential applications as an alternative and low-cost adsorbent for the removal of zinc(II) ions from aqueous solutions.

Acknowledgments: This work was financially supported by the National Natural Science Foundation of China (21467021); Leading Program of Science and Technology of Inner Mongolia (2016-fiance), Leading Program of Science and Technology of Inner Mongolia (20140401), and Leading Program of Science and Technology of Inner Mongolia (20140609); Project of Grasslands Outstanding Person of Inner Mongolia (2013) and Program of R\&D Team Building of Inner Mongolia (2014).

Author Contributions: Z.X.T. and W.X.M. conceived and designed the experiments; Z.X.T. and H.Y.N. performed the experiments; Z.X.T. and W.X.M. analyzed the data; W.X.M. and C.Z.J. contributed reagents/materials tools; Z.X.T., H.Y.N., W.X.M. and C.Z.J. wrote the paper.

Conflicts of Interest: The authors declare that they have no competing interests.

\section{References}

1. Hawari, A.; Rawajfih, Z.; Nsour, N. Equilibrium and thermodynamic analysis of zinc ions adsorption by olive oil mill solid residues. J. Hazard. Mater. 2009, 168, 1284-1289. [CrossRef] [PubMed]

2. Lalhruaitluanga, H.; Jayaram, K.; Prasad, M.N.; Kumar, K.K. Lead(II) adsorption from aqueous solutions by raw and activated charcoals of Melocanna baccifera Roxburgh (bamboo)-A comparative study. J. Hazard. Mater. 2010, 175, 311-318. [CrossRef] [PubMed]

3. Wahby, A.; Abdelouahab-Reddam, Z.; El Mail, R.; Stitou, M.; Silvestre-Albero, J.; Sepúlveda-Escribano, A. Mercury removal from aqueous solution by adsorption on activated carbons prepared from olive stones. Adsorption 2011, 17, 603-609. [CrossRef]

4. Shinde, N.R.; Bankar, A.V.; Kumar, A.R.; Zinjarde, S.S. Removal of Ni(II) ions from aqueous solutions by biosorption onto two strains of Yarrowia lipolytica. J. Environ. Manag. 2012, 102, 115-124. [CrossRef] [PubMed]

5. Minceva, M.; Fajgar, R.; Markovska, L.; Meshko, V. Comparative study of $\mathrm{Zn}^{2+}, \mathrm{Cd}^{2+}, \mathrm{Pb}^{2+}$ removal from water solution using natural clinoptilolitic zeolite and commercial granulated activated carbon equilibrium of adsorption. Sep. Sci. Technol. 2008, 43, 2117-2143. [CrossRef] 
6. Puzii, A.M.; Stavitskaya, S.S.; Poddubnaya, O.I.; Vikarchuk, V.M.; Tsyba, N.N. Structural and adsorption properties of active carbon from coconut shells modified with phosphorus heteroatoms. J. Therm. Anal. Calorim. 2016, 124, 1-16. [CrossRef]

7. Lin, J.; Wu, Z.; Tseng, W. Extraction of environmental pollutants using magnetic nanomaterials. Anal. Methods 2010, 2, 1874-1879. [CrossRef]

8. Depci, T.; Kul, A.R.; Önal, Y. Competitive adsorption of lead and zinc from aqueous solution on activated carbon prepared from Van apple pulp: Study in single- and multi-solute systems. Chem. Eng. J. 2012, 200, 224-236. [CrossRef]

9. Linares-Solano, A.; López-González, J.D.D.; Molina-Sabio, M.; Rodriguez-Reinoso, F. Active carbons from almond shells as adsorbents in gas and liquid phases. J. Chem. Technol. Biotechnol. 2010, 30, 65-72. [CrossRef]

10. Kikuchi, Y.; Qian, Q.; Machida, M.; Tatsumoto, H. Effect of $\mathrm{ZnO}$ loading to activated carbon on $\mathrm{Pb}(\mathrm{II})$ adsorption from aqueous solution. Carbon 2006, 44, 195-202. [CrossRef]

11. Bansode, R.R.; Losso, J.N.; Marshall, W.E.; Rao, R.M.; Portier, R.J. Adsorption of metal ions by pecan shell-based granular activated carbons. Bioresour. Technol. 2003, 89, 115-119. [CrossRef]

12. Nakagawa, Y.; Molina-Sabio, M.; Rodríguez-Reinoso, F. Modification of the porous structure along the preparation of activated carbon monoliths with $\mathrm{H}_{3} \mathrm{PO}_{4}$ and $\mathrm{ZnCl}_{2}$. Microporous Mesoporous Mater. 2007, 103, 29-34. [CrossRef]

13. Manjula, D.M. Heavy Metals Removal from Industrial Wastewater by Nano Adsorbent Prepared from Cucumis Melopeel Activated Carbon. J. Nanomed. Res. 2017, 5, 00102. [CrossRef]

14. Cronje, K.J.; Chetty, K.; Carsky, M.; Sahu, J.N.; Meikap, B.C. Optimization of chromium (VI) sorption potential using developed activated carbon from sugarcane bagasse with chemical activation by zinc chloride. Desalination 2011, 275, 276-284. [CrossRef]

15. Issabayeva, G.; Aroua, M.K.; Sulaiman, N.M. Removal of lead from aqueous solutions on palm shell activated carbon. Bioresour. Technol. 2006, 97, 2350-2355. [CrossRef] [PubMed]

16. Rahman, M.M.; Awang, M.; Mohosina, B.S.; Kamaruzzaman, B.Y.; Nik, W.B.W.; Adnan, C.M.C. Waste palm shell converted to high efficient activated carbon by chemical activation method and its adsorption capacity tested by water filtration. APCBEE Procedia 2012, 1, 293-298. [CrossRef]

17. Gonçalves, M.; Sánchez-García, L.; Oliveira Jardim, E.D.; Silvestre-Albero, J.; Rodríguez-Reinoso, F. Ammonia removal using activated carbons: Effect of the surface chemistry in dry and moist conditions. Environ. Sci. Technol. 2014, 45, 10605-10610. [CrossRef]

18. Wang, X.; Hao, Y.; Ding, L.; Xue, Z. The Preparation Method and Application of Xanthoceras Sorbifolia Bunge Hull Activated Carbon Loaded with KOH. Chiana Patent ZL2011100844764, 17 January 2013.

19. Romero-Anaya, A.J.; Lillo-Ródenas, M.A.; Lecea, S.M.D.; Linares-Solano, A. Hydrothermal and conventional $\mathrm{H}_{3} \mathrm{PO}_{4}$ activation of two natural bio-fibers. Carbon 2012, 50, 3158-3169. [CrossRef]

20. Zhang, J.; Wang, A. Adsorption of $\mathrm{Pb}(\mathrm{II})$ from aqueous solution by Chitosan-g-poly(acrylic acid)/Attapulgite/Sodium humate composite hydrogels. J. Chem. Eng. Data 2010, 55, 2379-2384. [CrossRef]

21. Yang, J.G. Heavy metal removal and crude bio-oil upgrading from sedum plumbizincicola harvest using hydrothermal upgrading process. Bioresour. Technol. 2010, 101, 7653-7657. [CrossRef] [PubMed]

22. Wang, Q.; Li, J.; Chen, C.; Ren, X.; Hu, J.; Wang, X. Removal of cobalt from aqueous solution by magnetic multiwalled carbon nanotube/iron oxide composites. Chem. Eng. J. 2011, 174, 126-133. [CrossRef]

23. Myglovetsa, M.; Poddubnayaa, O.I.; Sevastyanovac, O.; Lindströmc, M.E.; Gawdzikd, B.; Sobiesiakd, M.; Tsybaa, M.M.; Sapsaye, V.I.; Klymchuke, D.O.; Puziy, A.M. Preparation of carbon adsorbents from lignosulfonate by phosphoric acid activation for the adsorption of metal ions. Carbon 2014, 80, 771-783. [CrossRef]

24. Khan, M.A.; Ngabura, M.; Choong, T.S.; Masood, H.; Chuah, L.A. Biosorption and desorption of nickel on oil cake: Batch and column studies. Bioresour. Technol. 2012, 103, 35-42. [CrossRef] [PubMed]

25. Horsfall, M.; Abia, A.A. Sorption of cadmium(II) and zinc(II) ions from aqueous solutions by cassava waste biomass (Manihot sculenta Cranz). Water Res. 2003, 37, 4913-4923. [CrossRef] [PubMed]

26. Shahryari, Z.; Goharrizi, A.S.; Azadi, M. Experimental study of methylene blue adsorption from aqueous solutions onto carbon nano tubes. Int. J. Water Resour. Environ. Eng. 2010, 2, 016-028.

27. Karagoz, S.; Tay, T.; Ucar, S.; Erdem, M. Activated carbon from waste biomass by sulfuric acid activation and their use on methylene blue adsorption. Bioresour. Technol. 2008, 99, 6214-6222. [CrossRef] [PubMed]

28. Rodriguez, A.; Garcia, J.; Ovejero, G.; Mestanza, M. Adsorption of anionic and cationic dyes on activated carbon from aqueous solutions: Equilibrium and kinetics. J. Hazard. Mater. 2009, 172, 1311-1320. [CrossRef] 
29. Ramalingam, S.; Parthiban, L.; Rangasamy, P. Biosorption Modeling with Multilayer Perceptron for Removal of Lead and Zinc Ions Using Crab Shell Particles. Arab. J. Sci. Eng. 2014, 39, 8465-8475. [CrossRef]

30. Mishra, V.; Balomajumder, C.; Agarwal, V.K. Biosorption of Zn(II) onto the surface of non-living biomasses: A comparative study of adsorbent particle size and removal capacity of three different biomasses. Water Air Soil Pollut. 2010, 211, 489-500. [CrossRef]

31. Fernandez, E.; Hugi-Cleary, D.; López-Ramón, M.V.; Stoeckli, F. Adsorption of phenol from dilute and concentrated aqueous solutions by activated carbons. Langmuir 2003, 19, 9719-9723. [CrossRef]

32. Rozada, F.; Otero, M.; García, A.I.; Morán, A. Application in fixed-bed systems of adsorbents obtained from sewage sludge and discarded tyres. Dyes Pigment 2007, 72, 47-56. [CrossRef]

33. Sandesh, K.; Kumar, R.S.; Jagadeeshbabu, P.E. Rapid removal of cobalt (II) from aqueous solution using cuttle fish bones; equilibrium, kinetics, and thermodynamic study. Asia-Pac. J. Chem. Eng. 2013, 8, 144-153. [CrossRef]

34. Singha, B.; Das, S.K. Biosorption of $\mathrm{Cr}(\mathrm{VI})$ ions from aqueous solutions: Kinetics, equilibrium, thermodynamics and desorption studies. Colloids Surf. B Biointerfaces 2011, 84, 221-232. [CrossRef] [PubMed]

35. Xu, D.; Tan, X.L.; Chen, C.L.; Wang, X.K. Adsorption of Pb(II) from aqueous solution to MX-80 bentonite: Effect of $\mathrm{pH}$, ionic strength, foreign ions and temperature. Appl. Clay Sci. 2008, 41, 37-46. [CrossRef]

36. Chakraborty, S.S.; Maiti, N.; Mandal, B.M.; Bhattacharyya, S.N. Miscibility and phase diagrams for poly(vinyl methyl ether) and polyacrylate blend systems. Polymer 1993, 34, 111-114. [CrossRef]

37. Rana, D.; Mandal, B.M.; Bhattacharyya, S.N. Analogue calorimetry of polymer blends: Poly(styreneco-acrylonitrile) and poly(phenyl acrylate) or poly(vinyl benzoate). Polymer 1996, 37, 2439-2443. [CrossRef]

38. Rana, D.; Mandal, B.M.; Bhattacharyya, S.N. Analogue Calorimetric Studies of Blends of Poly(vinyl ester)s and Polyacrylates. Macromolecules 1996, 29, 1579-1583. [CrossRef]

39. Febrianto, J.; Kosasih, A.N.; Sunarso, J.; Ju, Y.H.; Indraswati, N.; Ismadji, S. Equilibrium and kinetic studies in adsorption of heavy metals using biosorbent: A summary of recent studies. J. Hazard. Mater. 2009, 162, 616-645. [CrossRef] [PubMed]

40. Gill, R.; Mahmood, A.; Nazir, R. Biosorption potential and kinetic studies of vegetable waste mixture for the removal of nickel(II). J. Mater. Cycles Waste Manag. 2013, 15, 115-121. [CrossRef]

41. Morsy, R. Synthesis and physicochemical evaluation of hydroxyapatite gel biosorbent for toxic $\mathrm{Pb}$ (II) removal from wastewater. Arab. J. Sci. Eng. 2016, 41, 2185-2191. [CrossRef]

42. Daifullah, A.A.M.; Girgis, B.S. Impact of surface characteristics of activated carbon on adsorption of BTEX. Colloids Surf. A 2003, 214, 181-193. [CrossRef]

43. Deng, L.; Su, Y.; Su, H.; Wang, X.; Zhu, X. Sorption and desorption of lead (II) from wastewater by green algae Cladophora fascicularis. J. Hazard. Mater. 2007, 143, 220-225. [CrossRef]

44. Bulut, Y.; Tez, Z. Adsorption studies on ground shells of hazelnut and almond. J. Hazard. Mater. 2007, 149, 35-41. [CrossRef] [PubMed]

45. Molina-Sabio, M.; Gonçalves, M.; Rodríguez-Reinoso, F. Oxidation of activated carbon with aqueous solution of sodium dichloroisocyanurate: Effect on ammonia adsorption. Microporous Mesoporous Mater. 2011, 142, 577-584. [CrossRef]

46. Lu, C.Y.; Chiu, H.S. Adsorption of zinc(II) from water with purified carbon nanotubes. Chem. Eng. Sci. 2006, 61, 1138-1145. [CrossRef]

47. Kathrine, C.; Hansen, H.C.B. Sorption of zinc and lead on coir. Bioresour. Technol. 2007, 98, 89-97. [CrossRef]

48. Ghoul, M.; Bacquet, M.; Morcellet, M. Uptake of heavy metals from synthetic aqueous solutions using modified PE1-silica gels. Water Res. 2003, 37, 729-734. [CrossRef]

49. Kargi, F.; Cikla, S. Biosorption of zinc(II) ions onto powdered waste sludge (PWS): Kientics and isotherm. Enzym. Microb. Technol. 2006, 38, 705-710. [CrossRef]

50. Coleman, N.J.; Lee, W.E.; Slipper, I.J. Interactions of aqueous $\mathrm{Cu}^{2+}, \mathrm{Zn}^{2+}$ and $\mathrm{Pb}^{2+}$ ions with crushed concrete fines. J. Hazard. Mater. 2005, 121, 203-213. [CrossRef] [PubMed]

(C) 2017 by the authors. Licensee MDPI, Basel, Switzerland. This article is an open access article distributed under the terms and conditions of the Creative Commons Attribution (CC BY) license (http:// creativecommons.org/licenses/by/4.0/). 